\title{
Status of substance abuse literacy in manufacturing and production sites in Iran: Results from a nationwide survey
}

\author{
Behzad Damari ${ }^{1}$, Ali Azimi ${ }^{2}$, Narges Salehi Shahrabi*1 \\ Received: 20 Aug 2018 \\ Published: 18 Feb 2019
}

\begin{abstract}
Background: Due to highly risk-taking behaviors such as alcohol and drug use status of health literacy at workplace is a major concern for health policy makers. Substance abuse literacy (SAL) includes the individuals' skills to obtain, understand and use substance-relevant health information. This will help to establish a healthy communication in a workplace setting and developing professional knowledge on workplace safety regulations, risky approaches and behaviours that may hurt the community workers. Since poor SAL status would inevitably cause serious harms to both community workers' health and facilities this study aimed to determine the status of SAL among manufacturing and production workers in Iran.

Methods: This is a nationwide cross-sectional survey conducted on 13,600 subjects who were selected through simple randomization into 380 workplaces in 31 provinces of Iran during February 2015 to January 2016. Data were collected through an author-made structured questionnaire by some trained interviewers. The study tool was developed using the literature and then sent to some experts for approving internal validity; minor changes were applied. Internal reliability test in 30 samples yielded Cronbach's alpha of 0.82 . All the questionnaires were administered at the participants' workplaces following obtaining their consent on releasing blinded information.

Results: Given that the score range was from 1 to 5, the mean for SAL in substance abuse was 4.04, so that the highest and lowest means were related to East Azerbaijan (4.22 \pm 0.74$)$ and Hormozgan (3.69 \pm 0.73$)$ provinces, respectively.

Conclusion: This study revealed that the Iranian workers SAL status was fairly high despite the reported high rate of substance abuse $(30 \%)$ among Iranian workforces. This apparently contradictory finding could be resolved using Syndemics in which refers to clustering of several issues in a society that contribute to and result from socioeconomic and cultural factors and inequalities Therefore, it is still necessary for policy makers and other researchers to take this issue into consideration in Iranian manufacturing and production plants.
\end{abstract}

Keywords: Substance abuse literacy, Health literacy, Iranian worker, Production site

Conflicts of Interest: None declared

Funding: Ministry of Cooperatives, Labour, and Social Welfare

*This work has been published under CC BY-NC-SA 1.0 license

Copyright $\odot$ Iran University of Medical Sciences

Cite this article as: Damari B, Azimi A, Salehi Shahrabi N. Status of substance abuse literacy in manufacturing and production sites in Iran: Results from a nationwide survey. Med J Islam Repub Iran. 2019 (18 Feb);33:7. https://doi.org/10.47176/mjiri.33.7

\section{Introduction}

Health literacy has been evolved from 1970's and appeared in a variety of disciplines most notably medical education, healthcare policy-making, library science, public and occupational health, and mental health, as well (1). American Institute of Medicine has defined the health literacy (HL) as the "degree to which individuals have the

Corresponding author: Dr Narges Salehi Shahrabi, nargesalehi@gmail.com

1. Brain and Spinal Cord Injury Research Center, Neuroscience Institute, Tehran University of Medical Sciences, Tehran, Iran, \& Governance and Health Department, Tehran, Iran

2. Department of Knowledge and Information Science, School of Psychology and Education, Kharazmi University, Tehran Iran capacity to obtain, process and understand basic health information and services needed to make appropriate health decisions" (2). The definition points at the term "literacy" as the "capacity to obtain, process and understand", while in the 2015 American Association of College and Research Libraries (ACRL) updated the defini-

\section{$\uparrow$ What is "already known" in this topic:}

The rate of substance abuse in Iranian workplace is reported to be high $(33 \%)$ and this denotes that the Iranian workforce substance abuse literacy is limited.

\section{$\rightarrow$ What this article adds:}

It was revealed that the status of Iranian workers' SAL is overall high, though this is not enough and there might have been a variety of other factors affecting the rate of substance abuse in Iran. 
tion and moved beyond the basic "need-search-find-use" cliché and put a greater emphasis on creation, value and the ethical issues surrounding it (3).

In terms of ontology, health literacy (HL) or health information literacy (HIL) is an umbrella term for substance abuse literacy (SAL) known also as addiction information literacy (3). Based on a proposed model in 2012 (5), HL includes 12 dimensions of knowledge, motivation, competence assessment, understanding, encouragement and application of health-related information for care, prevention, and promotion.

While it is highly critical for the wellbeing of the people and society, unfortunately, health literacy is not well addressed in many modern societies (9). According to the WHO (6), modern societies actively market unhealthy lifestyle and their education systems too often fail to provide people with reliable health information literacy. This paradox has led a dramatic increase in healthcare expenditures worldwide. For instance, Eichler et al (8) reported that the burden of low-level health literacy on the healthcare system level ranges from 3 to $5 \%$ of healthcare total cost per year and on the patients' level ranges from US $\$ 143$ to 7,798 per person per year (8).

HL limitations may cause several complications such as lack of accessibility to appropriate health services, less willingness to follow treatment, low medication coherence, increasing the emergency presentation, increasing the treatment period in hospital, and high mortality rate (6, 8). Also, according to the WHO's "Solid Facts" book, weak health literacy may result in less healthy choices, riskier behavior, poorer health, less self-management and more hospitalization (6). Thus, limited health literacy is a silent killer hiding behind all health-related issues (7).

In a national study (10), it was revealed that about $40 \%$ of Iran's population had limited health literacy, mostly in vulnerable groups including the elderly, housewives, unemployed people and people with limited general literacy. Health literacy in the workplace, as the third place (the two others being home and school), points at the importance of organizational responsibilities in educating workers to access, appraise and apply health information on individual and occupational health concerns (11). Many studies have examined the consequences of limited health literacy in the incidence of diabetes, asthma, cancer, cardiovascular disease and mental disorders, while a few studies are performed on the association between the prevalence of substance abuse and health literacy (12) (Lincoln et al. 2006).

Given the increasing growth of substance use in the workplace, substance abuse literacy could be one of the effective toolkits to prevent the abuse of narcotics (13). In a study (14) to evaluate SAL programs in the workplace in five Iran's provinces, most important achievements were increasing the status of awareness and sensitivity of employees and employers to substance abuse, and increasing productivity, reduction of absenteeism and leave.

The Ministry of Health and Medical Education jointly with Department of Cultural and Social Affairs of the Ministry of Labor, Social Co-operation and Social Welfare and the Welfare Organization recently has released a document to report the prevalence of substance abuse at the Iranian workplaces to be $33 \%$ in 2015 (15). Since the prevalence of substance abuse is highly critical, this research aimed to measure the SAL of Iranian community of workers in manufacturing and production sites.

\section{Methods}

This study was a quantitative survey conducted in 31 provinces of Iran. The data were collected by the trained interviewers through an interview-based author-made structured questionnaire .Sorensen et al (16) in a study on $\mathrm{HL}$ in Europe explained the process of designing a HL questionnaire. They categorized HL competencies in three fields including healthcare, prevention of disease and health promotion related to the accessibility to healthrelated information, the ability to understand healthrelated information, the ability to evaluate health information and the utility of health-related information.

The current research tool was developed on the bases of Sorensen et al and some similar ones, e.g. $(17,18)$. The SAL questionnaire used in this survey has eleven questions designed by the researchers. The questions included the eleven false beliefs about substance abuse to specify how much respondents would agree with each item with 6-point Likert type scale including very much, much, average, low, very low, and no idea . The content validity of this questionnaire was verified in an expert panel of which yielded CVR of 0.89 and CVI of 0.87 .In order to reduce the measurement error, the intended correct answer for questions 1, 2, 4 and 6 to 11 was assigned to be "very low", and in questions 3 and 5 "very much". Also, for the questionnaire filling out needed, feasibility of the study, face validity and possible problems of the questionnaire, a pilot study was conducted in two workshops in Tehran province with a sample size of 30 people in each workshop .The Cronbach's alpha was 0.82 .

To determine the sample size in each province, considering Alpha (type I error) of 0.05 and prevalence of 0.5 , 400 samples were needed. For the three provinces of Razavi Khorasan, Tehran and Isfahan, because of the large number of workers, 13600 samples (almost double) in total were considered (Table 1). Sampling method was randomization using random number table. Also, in each province, the workshops were randomly selected from the list of workshops.

To minimize survey error, all interviewers participated in a one-day workshop before performing the survey and were educated to learn how to properly administer the questionnaire. The data were inputted by two independent computer operators and analyzed through SPSS software version 20 .

\section{Results}

In this survey, 13,842 questionnaires were completed in 380 workplaces in 31 provinces of Iran. Of the total number of samples, $85.5 \%$ were male and $14.5 \%$ were female with an average working experience of 11.3 years. In order to compute responses, the range of points was from 1 to 5 including "Very much $=1$, Much $=2$, Average $=3$, Low $=4$, and Very Low $=5 "$. For questions 1, 2, 4 and 6 


\begin{tabular}{lccccc}
\multicolumn{5}{l}{ Table 1. The number of samples in each province } \\
\hline Code & Province & $\mathrm{N}$ & Code & Province & $\mathrm{N}$ \\
\hline 01 & Khuzestan & 400 & 17 & Kohkiluyeh and Boyer-Ahmad & 400 \\
02 & North Khorasan & 400 & 18 & Lorestsn & 400 \\
03 & Gilan & 400 & 19 & Markazi & 400 \\
04 & Ilam & 400 & 20 & Chaharmahal and Bakhtiari & 400 \\
05 & Yazd & 400 & 21 & Hormozgan & 400 \\
06 & Sistan and Baluchestan & 400 & 22 & Hamadan & 400 \\
07 & Zanjan & 400 & 23 & Qazvin & 400 \\
08 & Semnan & 400 & 24 & Qom & 400 \\
09 & Bushehr & 400 & 25 & West Azerbaijan & 400 \\
10 & Razavi Khorasan & 800 & 26 & East Azerbaijan & 400 \\
11 & South Khorasan & 400 & 27 & Ardabil & 400 \\
12 & Golestan & 400 & 28 & Isfahan & 800 \\
13 & Kurdistan & 400 & 29 & Alborz & 400 \\
14 & Kerman & 400 & 30 & Shiraz & 400 \\
15 & Kermanshah & 400 & 31 & Mazandaran & 400 \\
16 & Tehran & 800 & & Total & 13600 \\
\hline
\end{tabular}

\begin{tabular}{|c|c|c|c|}
\hline Province & $\mathrm{N}$ & Mean & Standard deviation \\
\hline East Azerbaijan & 404 & 4.22 & 0.74157 \\
\hline West Azerbaijan & 448 & 4.12 & 0.80927 \\
\hline Ardabil & 446 & 4.07 & 0.90555 \\
\hline Isfahan & 808 & 4.06 & 0.85651 \\
\hline Alborz & 403 & 4.20 & 0.78491 \\
\hline Ilam & 400 & 4.02 & 0.85472 \\
\hline Bushehr & 415 & 4.06 & 0.99028 \\
\hline Tehran & 836 & 4.01 & 0.86813 \\
\hline Chaharmahal and Bakhtiari & 390 & 4.01 & 0.75210 \\
\hline South Khorasan & 404 & 4.17 & 0.74634 \\
\hline Razavi Khorasan & 813 & 4.08 & 0.81475 \\
\hline North Khorasan & 398 & 4.01 & 0.88460 \\
\hline Khuzestan & 401 & 4.17 & 0.90844 \\
\hline Zanjan & 400 & 4.06 & 0.87439 \\
\hline Semnan & 373 & 4.08 & 0.75243 \\
\hline Sistan and Baluchestan & 400 & 3.92 & 0.93461 \\
\hline Shiraz & 400 & 4.05 & 0.90607 \\
\hline Qazvin & 384 & 4.07 & 0.88422 \\
\hline Qom & 402 & 4.08 & 0.74918 \\
\hline Kurdistan & 400 & 4.10 & 0.72556 \\
\hline kerman & 400 & 3.97 & 0.93997 \\
\hline kermanshah & 418 & 3.88 & 0.89492 \\
\hline Kohgiluyeh and Boyer-Ahmad & 401 & 4.04 & 0.72772 \\
\hline Golestan & 400 & 4.00 & 0.90683 \\
\hline Gilan & 388 & 3.98 & 1.01193 \\
\hline Lorestsn & 405 & 4.05 & 0.81850 \\
\hline Mazandaran & 404 & 4.02 & 0.80201 \\
\hline Markazi & 421 & 4.15 & 0.73826 \\
\hline Hormozgan & 397 & 3.59 & 0.72833 \\
\hline Hamadan & 398 & 3.87 & 0.89174 \\
\hline Yazd & 485 & 4.16 & 0.70408 \\
\hline Total & 13842 & 4.04 & 0.84 \\
\hline
\end{tabular}

Source: National survey of the literacy of addiction prevention in the work and production Society in 2016

to 11 the order of answers were reversed to "Very Low = 1, Low $=2$, Average $=3$, Much $=4$, Very much $=5 "$.

According to the results, the average national rate of workplace SAL was 4.04 (out of 5). The provi ncial averages are shown in Table 2, where highest SAL mean was for East Azerbaijan (4.22 \pm 0.74$)$ and the lowest for Hormozgan $(3.69 \pm 73)$ provinces. Figure 1 presents the provinces by either yellow or green colors, where the yellow denotes below the average level and green above the average level.

The results of the statistical analysis of the 11 questions are shown in Table 3, where the highest wrong answer (lowest score) was for seventh question: "Anyone can easily quit substance abuse forever" followed by the third question: "Drug offer by colleagues and boss never should be accepted at the workplace".

\section{Discussion}

This survey was conducted to evaluate the level of SAL in manufacturing and production sites before any intervention and thus reports the existing Iran's national workplace SAL to be 4.04 .The highest wrong answer (lowest score) was for seventh question of "Anyone can easily quit the drug addiction forever". Newman (19) has reviewed cognitive models of quitting addiction including self-efficacy (indicating the individual judgment about the 


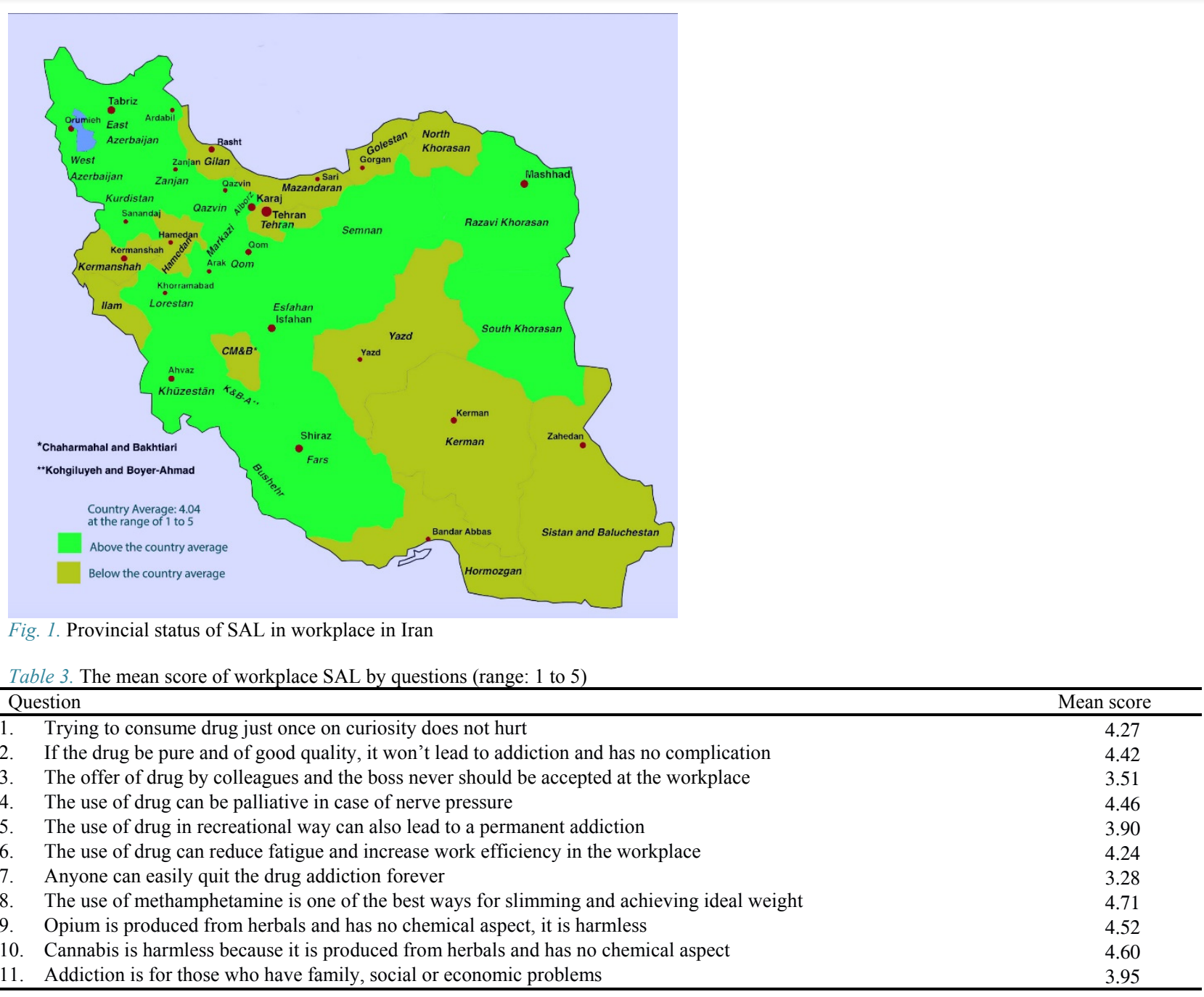

ability to face challenges and risk conditions), expectations of predicted outcomes (indicating the individual's guesses about the effects of use and/or non-use of the narcotics), reasons (indicating the individual's judgment of the external and internal causes for the consumption or quitting the narcotics) and the decision-making process (indicating the effect of multiple decisions on the consumption or quitting the narcotics.

The second most incorrect answer was for to the third question of "The offer of drug by colleagues and the boss never should be accepted at the workplace", in which depicts the role of peer pressure to substance. In line with current study, Yadav et al (20) showed that the primary reasons to take up smoking among Delhi university students had been pleasurable experience, adding to intimacy and peer pressure. Another study (21) suggested that limited health literacy may be a significant and independent risk factor for smoking in individuals with a low socioeconomic status. In a study performed on the underlying reasons for substance abuse in workplaces in Iran, Damari et al (22) proposed a national-based survey to clarify dimensions of substance abuse in Iran to help policymakers.

Overall, major studies confirm the positive role of HL in improving the individuals' health by preventing substance abuse and taking up narcotic materials habit. For instance,
Rogers et al (23) in a very recent study showed that HL significantly negatively is associated with opioid misuse. As they claimed, substance abuse has become a growing epidemic in the US and interventions targeting people's HL may help to address the crisis.

According to Syndemics, in which multiple health issues (such as drug abuse, AIDs, and violence) interact with each other and with the sociocultural and economic problems (24), one cannot overcome the complex problem of addiction by investing in just an intervention. A cluster of preventive and supportive policies are needed to act effectively against substance abuse and related problems.

\section{Conclusion}

In spite of the high level of SAL, the prevalence of addiction is still high in Iran (15). Therefore, it seems that just having a health literate people is not sufficient to prevent substance abuse in an effective manner. To this regard, some suggestions are presented below to address the issue, as follows; A proper investment in prohibitory measures and condign actions to reduce drugs supply, budgeting health promotion programs sufficiently to reduce drugs demands (e.g. for reducing pain), improving the society's political, economic, social and international relations to relieve mental disorders and diseases, provid- 
ing supportive data for policymakers so that they be able to decide in an evidence-base manner, and including the HL test results for future job opportunities and funds allocations. Damari et al (25) also suggests that increasing the income and improving the status of welfare and recreation facilities, and modification of sexual health status which is currently low due to the prevalence of sexual dysfunctions in men and women (20-40\%) are other effective measures.

Major HL studies have been conducted on the relationship between HL and the incidence of disease, but the present study firstly investigated the dimensions of the addiction prevention, and then examined the extent of workplace SAL in the manufacturing and production sites in Iran. To the best of our knowledge, this study is genius for both the studied sample size and the covered subject; the SAL.

\section{Conflicts of interest}

The authors declare no conflict of interest.

\section{Ethical considerations}

Ethical issues (including plagiarism, data fabrication, double publication) have been completely observed by the authors.

\section{Funding/Support}

Ministry of Cooperatives, Labour, and Social Welfare.

\section{References}

1. Mancuso JM. Health literacy: a concept/dimensional analysis. Nurs Health Sci. 2008;10(3):248-55.

2. Schardt C. Health information literacy meets evidence-based practice. J Med Lib Assoc. 2011;99(1):1-2.

3. Bejarano W, Ward JH. CICAS: Toward a critical framework of information literacy in Addiction Science. Proceedings of the 38th Annual SALIS / AMHL Conference; 2016. Denvor, Colorado.

4. Murphy DA, Lam P, Naar-King S, Harris DR, Parsons JT, Muenz LR, et al. Health literacy and antiretroviral adherence among HIVinfected adolescents. Patient Educ Counsel. 2010;79(1):25-9.

5. Sørensen K, Van den Broucke S, Fullam J, Doyle G, Pelikan J, Slonska Z, et al. Health literacy and public health: a systematic review and integration of definitions and models. BMC Pub Health. 2012;12(1):80.

6. Kickbusch I, Pelikan JM, Apfel F, Tsouros AD, editors. Health literacy: The solid facts. Copenhagen, Denemark: WHO Regional Office for Europe; 2013.

7. Paasche-Orlow MK, Cheng DM, Palepu A, Meli S, Faber V, Samet JH. Health literacy, antiretroviral adherence, and HIV-RNA suppression. J Gen Intern Med. 2006;21(8):835-40.

8. Eichler K, Wieser S, Brügger U. The costs of limited health literacy: a systematic review. Int J Pub Health. 2009;54(5):313.

9. Fukuda H, Kitajima F, Sakamoto Y, Suwa K, Fujiwara A, Morita R. 1444 Health literacy in japanese workplace (2nd report): impact of workplace health promotion, lessons learned from the practice. Occup Environ Med. 2018;75(Suppl 2):A172-A.

10. Tavousi M, Haeri-Mehrizi A, Rafiifar Sh, Soleymanian A, Sarabadi F, Ardestani M, et al. Health literacy in Iran: Findings from a national study. Payesh. 2016;15(1):95-102.

11. Larsen AK, Holtermann A, Mortensen OS, Punnett L, Rod MH, Jørgensen MB. Organizing workplace health literacy to reduce musculoskeletal pain and consequences. BMC Nurs. 2015;14:46-.

12. Lincoln A, Paasche-Orlow MK, Cheng DM, Lloyd-Travaglini C, Caruso C, Saitz R, et al. Impact of health literacy on depressive symptoms and mental health-related: quality of life among adults with addiction. J Gen Intern Med. 2006;21(8):818-22.

13. Balch GI, Tworek C, Barker DC, Sasso B, Mermelstein RJ, Giovino
GA. Opportunities for youth smoking cessation: findings from a national focus group study. Nicotine Tob Res. 2004;6(1):9-17.

14. Damari B, Barati F, HajNagizade F, Gazarian M, A O. Evaluation of the 'substance abuse prevention program in workplaces. Payesh. 2014;13(2): 165-75.

15. Yaghoobi H, Alaeddini F, Esmaeeli I, Almadani H, Bostanmanesh Gh, Sadeghi M. Mental Health Status and Quality of Work Life in Industrial and Manufacturing Centers: A Survey on the Role of Job Stressors. Report. Tehran, Department of Cultural and Social Affairs of the Ministry of Labor SC-oaSWatWO; 2015.

16. Sørensen K, Van den Broucke S, Pelikan JM, Fullam J, Doyle G, Slonska Z, et al. Measuring health literacy in populations: illuminating the design and development process of the European Health Literacy Survey Questionnaire (HLS-EU-Q). BMC Pub Health. 2013;13(1):948.

17. Larsen AK, Holtermann A, Mortensen OS, Punnett L, Rod MH, Jørgensen MB. Organizing workplace health literacy to reduce musculoskeletal pain and consequences. BMC Nurs. 2015;14(1):46.

18. Yancey A, Tomiyama AJ, Keith N. Addressing diversity and health literacy at the worksite. ACSM'S worksite health handbook: A guide to building healthy and productive companies (2nd ed) Champaign, IL: Human Kinetics. 2009;1.

19. Newman CF. Cognitive therapy of substance abuse: Guilford Press; 2001.pp. 16

20. Yadav V, Sachdeva P, Handa S, Bhagat A, Malik M, Laller S. Substance abuse: Trends among university students in Delhi-NCR. Int J Cur Res. 2018;10(7):71201-4.

21. Stewart DW, Adams CE, Cano MA, Correa-Fernández V, Li Y, Waters AJ, et al. Associations between health literacy and established predictors of smoking cessation. Am J Pub Health. 2013;103(7):e43e9.

22. Damari B, Almadani H, Pishkuhi MA. Iranian drug use survey in workplaces: A study protocol. Medical journal of the Islamic Republic of Iran. 2018;32:93.

23. Rogers AH, Bakhshaie J, Orr MF, Ditre JW, Zvolensky MJ. Health Literacy, Opioid Misuse, and Pain Experience Among Adults with Chronic Pain. Pain Med. 2019.

24. Mendenhall E, Kohrt BA, Norris SA, Ndetei D, Prabhakaran D. Non-communicable disease syndemics: poverty, depression, and diabetes among low-income populations. The Lancet. 2017;389(10072):951-63.

25. Damari B, Tabrizchi N, Riazi-Isfahani S. Designing a national plan for improving sexual health in Iran: An experience of an Islamic country. Med J Islam Repub Iran. 2016;30:407. 